\title{
The Role of Pathology in Predicting Immunotherapy Response in Urogenital Tumors
}

\author{
(1D) Yasemin ÖZLÜK \\ Department of Pathology, İstanbul University, Istanbul Faculty of Medicine, İstanbul-Turkey
}

\begin{abstract}
SUMMARY
Immune checkpoint inhibitors (ICI) are recently introduced in the management of various cancers. There are three main immunotargets as follows: Cytotoxic T-lymphocyte antigen-4 (CTLA4), programmed death 1 (PD-1) and programmed death ligand-1 (PD-L1). These three targets are under investigation for therapeutic, predictive and prognostic purposes in genitourinary cancers. There is a need for predictive biomarkers of immunotherapy to optimize treatment, to limit side-effects and to reduce the costs of therapy. This review focuses on the role of pathologic applications in the selection of patients with genitourinary cancer who are potentially responsive to immunotherapy. PD-L1 expression by immunohistochemistry, tumor mutation burden and microsatellite instability status are mainly discussed.
\end{abstract}

Keywords: Cancer; genitourinary; immunotherapy; PD-L1; pathology.

Copyright $\odot$ 2020, Turkish Society for Radiation Oncology

\section{Introduction}

Core tip: Immunotherapy is getting more a part of the therapy algorithm among genitourinary cancers. There is a need for reliable predictive biomarkers to select a responsive group of patients. A single marker does not seem to be sufficient for patient selection. Pathology is gradually becoming more of a critical member of tumor boards, not just for diagnosis but also for the predictive and prognostic role along with the investment of new technologies. To obtain accurate and reliable results in the molecular analysis of the tumor, a strong pathologist-clinician relationship is mandatory for patient care.

The immune system has an important role in tumor pathogenesis, tumor growth and tumor metastasis.[1] Immune checkpoint inhibitors (ICI) are recently introduced in the management of various cancers, such as non-small cell lung cancer, renal cell carcinoma (RCC), urothelial carcinoma (UC), and head and neck squamous cell carcinoma. Several immunotherapeutic drugs have been approved by the Food and Drug Administration (FDA) and European Medicines Agency (EMA) in genitourinary cancers.[2]

There are three main immunotargets as follows: Cytotoxic T-lymphocyte antigen-4 (CTLA4), programmed death 1 (PD-1) and programmed death ligand-1 (PD-L1). These three targets are under investigation for therapeutic, predictive and prognostic purposes in genitourinary cancers. PD-1 is a negative immune checkpoint protein that is expressed on activated T-cells.[3] PD-L1, one of several ligands of PD-1 receptor, is expressed in the tissue. Binding of PD-1 and $\mathrm{PD}-\mathrm{L} 1$ results in the inhibition of cytotoxic $\mathrm{T}$ cell response. Overexpression of PD-L1 on the surface of tumor cells and tumor-infiltrating immune cells, and its engagement with PD-1 on T cells suppress T-cell-mediated tumor cytotoxicity. These inhibitory signals help the tumor to evade the immune system and to grow. $[3,4]$ The therapeutic blockade of the PD-1/PD-L1 pathway has been shown as an efficient and safe option 
for the management of cancer patients with impressive clinical outcomes. [5-8]

There is a need for predictive biomarkers of immunotherapy to optimize treatment, to limit side-effects and to reduce the costs of therapy. Thus, tissue-based PD-L1 assays have been developed as a companion biomarker for ICIs.[9-11] Although PD-L1 immunohistochemistry is widely used in the prediction of immunotherapy response, this methodology is not perfect. There are several other predictive biomarkers under investigation, including tumor mutation burden, mismatch repair status, gene expression profiles, tumor infiltrating lymphocytes (TILs) and PD-L2.

This review focuses on the role of pathologic applications in the selection of patients with genitourinary cancer (mainly RCC and UC) who are potentially responsive to immunotherapy.

\section{PD-L1}

The predictive value of expression of PD-L1 on tumor cells by immunohistochemistry is controversial. For each approved PD-1/PD-L1 drug, there is a paired immunohistochemistry-based PD-L1 assay. The presence of variance in PD-L1 assays and quantitative immunostaining thresholds poses a clinical challenge in routine practice. Critical issues for PD-L1 immunohistochemistry may be summarized in four categories [12]:

- Cellular component to be scored: tumor cells and/ or tumor-infiltrating immune cells

- Positivity threshold that is clinically meaningful

- Intratumoral and intertumoral heterogeneity of

PD-L1 expression

- Preanalytic technical challenges

The first three challenges listed above vary among different tumor types. Most data on genitourinary tumors accumulate in RCCs and UCs. The results of the PD-L1 assay may be discordant for an individual patient depending on the assay used. In one study, durvalumab was investigated in the second-line treatment of UC patients. The authors showed that PD-L1 results in only one component; immune cells or tumor cells did not cleanly separate responders and non-responders. However, when they took into account the PD-L1 status either in immune cells or tumor cells $(\geq 25 \%)$, a clear distinction could be made between responder and non-responder groups of the patients. [13] PD-L1 positivity in $\geq 5 \%$ of tumor cells has been shown to be associated with a response to avelumab in the second line.[14] In another study on atezolizumab among second-line treatment of advanced UC patients, PD-L1 expression on only immune cells was associated with response and longer survival.[15,16] PD-L1 expres- sion did not act as a predictive marker in the first-line treatment setting with atezolizumab.[17] The data on the predictive value of PD-L1 on response rate to pembrolizumab show conflicting results in the first and second lines for advanced urothelial carcinoma.[11,18]

Similar conflicting results have been shown for RCC patients. Response to nivolumab was not related to PD-L1 expression in advanced RCC patients in one study.[7] Treatment benefit of nivolumab was observed irrespective of PD-L1 status. Researchers also showed that although PD-L1 was not predictive, it may be prognostic.[19-21] Recent data also showed discordant results between primary and metastatic tumors, and, low and high-grade components of a tumor.[22] Another challenging issue is that prior treatment of VEGF and mTOR inhibitors modifies PD-L1 expression. [23,24]

PD-L1 expression testing additionally has technical challenges since PD-L1 testing usually is performed on archival specimens. $[25,26]$ Technical challenges include the time of fixation in formalin, variation in the affinity of the antibody used and standardization of the amplification systems. It is important to remember that the philosophy of 'tissue is the issue' in pathology practice and standardization of the routine procedures in a pathology laboratory is essential.

A summary of FDA-approved drugs and paired companion PD-L1 testing for UCs and RCCs is given in the Table 1. None of the immune checkpoint inhibitors has been approved for advanced prostate cancer yet.[27] Although metastatic castration-resistant prostate carcinomas show high PD-L1 expression in one third of biopsies, mostly in neuroendocrine and small cell carcinomas of the prostate,[28] response to PD-L1 inhibitors is not related to PD-L1 expression. [29,30]

\section{Tumor Mutation Burden (TMB) and Mismatch Repair Status}

Higher mutation burden is believed to be associated with an increase in the tumor antigens and these antigen-rich tumor cells may be recognized by the immune system more easily. TMB is defined as the total number of coding and somatic mutations, but also include insertions/deletions.[31] Preanalytic factors related to routine tissue preparing in a pathology laboratory may influence the results of TMB analysis. These factors are fixatives, fixation time, and tumor purity.

A better response to immunotherapy was observed in tumors with higher TMB, such as melanoma [32] and non-small cell lung cancer.[24] Because of the presence of similar limiting factors for both PD-L1 assays and TMB, it is suggested to use both predictive markers as complementary to each other.[31] 
Table 1 Summary of the literature data on immunohistochemical assays of PD-L1 with matched immune checkpoint drugs

\begin{tabular}{|c|c|c|c|c|c|}
\hline Drug & Clone & IHC assay & Positivity threshold & Cell component & Reference \\
\hline \multicolumn{6}{|c|}{ Urothelial carcinoma (advanced/metastatic) } \\
\hline Atezolizumab & SP142 & Ventana & $\geq 5 \%$ & IC & {$[15,17]$} \\
\hline Nivolumab & $28-8$ & Dako & $\geq 5 \%$ & $\mathrm{TC}$ & {$[8]$} \\
\hline Pembrolizumab & $22 \mathrm{C} 3$ & Dako & $\geq 10 \%$ & $\mathrm{IC} / \mathrm{TC}$ & {$[11,18]$} \\
\hline Avelumab & $73-10$ & Dako & $\geq 5 \%$ & $\mathrm{TC}$ & {$[14]$} \\
\hline Durvalumab & SP263 & Ventana & $\geq 25 \%$ & $\mathrm{IC} / \mathrm{TC}$ & [13] \\
\hline \multicolumn{6}{|c|}{ Renal cell carcinoma (advanced/metastatic) } \\
\hline Nivolumab & $28-8$ & Dako & $\geq 5 \%$ & $\mathrm{TC}$ & [7] \\
\hline
\end{tabular}

IHC: Immunohistochemistry; IC: Immune cells: TC: Tumor cells

RCC has been shown to have an intermediate level of TMB and a high prevalence of insertions/deletions. This specific type of mutations may result in a high expression of neoantigens and better recognition by the immune system. [31,33] Further studies showed better prediction of immunotherapy in metastatic UCs with high TMB. $[15,18]$

Cancers deficient in DNA mismatch-repair (dMMR) or microsatellite instability (MSI-high) demonstrate better benefit from immunotherapy. As expected, tumors with higher TMB also show dMMR or MSI-high status.[34,35] Based on clinical trials, the FDA has approved pembrolizumab therapy for solid tumors with dMMR or MSI-high, irrespective of tumor origin.[36]

MSI-high status is a major feature of hereditary non-polyposis colorectal cancer (HNPCC) syndrome. Among HNPCC syndrome patients, upper tract UCs are placed in the third rank.[37] Mismatch repair status and its relation to response to immunotherapy among genitourinary tumors are still under investigation.

\section{Conclusion}

Immunotherapy is getting more a part of the therapy algorithm among genitourinary cancers. There is a need for reliable predictive biomarkers to select a responsive group of patients. A single marker does not seem to be sufficient for patient selection. Gene expression profiles, PD-L2, tumor infiltrating cytotoxic $\mathrm{T}$ lymphocytes and gastrointestinal microbiome are other predictive markers that are under investigation in urogenital tumors. [38] Pathology is gradually becoming more of a critical member of tumor boards, not just for diagnosis but also for the predictive and prognostic role along with the investment of new technologies. To obtain accurate and reliable results in the molecular analysis of the tumor, a strong pathologist-clinician relationship is mandatory for patient care.

Peer-review: Externally peer-reviewed.

Conflict of Interest: No conflict of interest.

Financial Support: No financial support.

\section{References}

1. Montironi R, Santoni M, Cheng L, Lopez-Beltran A, Massari F, Matrana MR, et al. An Overview of Emerging Immunotargets of Genitourinary Tumors. Curr Drug Targets 2016;17(7):750-6.

2. Mehta K, Patel K, Parikh RA. Immunotherapy in genitourinary malignancies. J Hematol Oncol 2017;10(1):95.

3. Alsaab HO, Sau S, Alzhrani R, Tatiparti K, Bhise K, Kashaw SK, et al. PD-1 and PD-L1 Checkpoint Signaling Inhibition for Cancer Immunotherapy: Mechanism, Combinations, and Clinical Outcome. Front Pharmacol 2017;8:561.

4. Zitvogel L, Kroemer G. Targeting PD-1/PD-L1 interactions for cancer immunotherapy. Oncoimmunology 2012;1(8):1223-5.

5. Garon EB, Rizvi NA, Hui R, Leighl N, Balmanoukian AS, Eder JP, et al. Pembrolizumab for the treatment of non-small-cell lung cancer. N Engl J Med 2015;372(21):2018-28.

6. Ferris RL, Blumenschein G Jr, Fayette J, Guigay J, Colevas AD, Licitra L, et al. Nivolumab for Recurrent Squamous-Cell Carcinoma of the Head and Neck. N Engl J Med 2016;375(19):1856-67.

7. Motzer RJ, Escudier B, McDermott DF, George S, Hammers HJ, Srinivas S, et al. Nivolumab versus Everolimus in Advanced Renal-Cell Carcinoma. N Engl J Med 2015;373(19):1803-13. 
8. Sharma P, Callahan MK, Bono P, Kim J, Spiliopoulou $P$, Calvo E, et al. Nivolumab monotherapy in recurrent metastatic urothelial carcinoma (CheckMate 032): a multicentre, open-label, two-stage, multi-arm, phase 1/2 trial. Lancet Oncol 2016;17(11):1590-8.

9. Reck M, Rodríguez-Abreu D, Robinson AG, Hui R, Csőszi T, Fülöp A, et al. Pembrolizumab versus Chemotherapy for PD-L1-Positive Non-Small-Cell Lung Cancer. N Engl J Med 2016;375(19):1823-33.

10. Herbst RS, Baas P, Kim DW, Felip E, Pérez-Gracia JL, Han JY, et al. Pembrolizumab versus docetaxel for previously treated, PD-L1-positive, advanced non-smallcell lung cancer (KEYNOTE-010): a randomised controlled trial. Lancet 2016;387(10027):1540-50.

11. Bellmunt J, de Wit R, Vaughn DJ, Fradet Y, Lee JL, Fong L, et al. Pembrolizumab as Second-Line Therapy for Advanced Urothelial Carcinoma. N Engl J Med 2017;376(11):1015-26.

12. Hansen AR, Siu LL. PD-L1 Testing in Cancer: Challenges in Companion Diagnostic Development. JAMA Oncol 2016;2(1):15-6.

13. Massard C, Gordon MS, Sharma S, Rafii S, Wainberg ZA, Luke J, et al. Safety and Efficacy of Durvalumab (MEDI4736), an Anti-Programmed Cell Death Ligand-1 Immune Checkpoint Inhibitor, in Patients With Advanced Urothelial Bladder Cancer. J Clin Oncol 2016;34(26):3119-25.

14. Apolo AB, Infante JR, Balmanoukian A, Patel MR, Wang D, Kelly K, et al. Avelumab, an Anti-Programmed Death-Ligand 1 Antibody, In Patients With Refractory Metastatic Urothelial Carcinoma: Results From a Multicenter, Phase Ib Study. J Clin Oncol 2017;35(19):2117-24.

15. Rosenberg JE, Hoffman-Censits J, Powles T, van der Heijden MS, Balar AV, Necchi A, et al. Atezolizumab in patients with locally advanced and metastatic urothelial carcinoma who have progressed following treatment with platinum-based chemotherapy: a single-arm, multicentre, phase 2 trial. Lancet 2016;387(10031):1909-20.

16. Powles T, Eder JP, Fine GD, Braiteh FS, Loriot Y, Cruz C, et al. MPDL3280A (anti-PD-L1) treatment leads to clinical activity in metastatic bladder cancer. Nature 2014;515(7528):558-62.

17. Balar AV, Galsky MD, Rosenberg JE, Powles T, Petrylak DP, Bellmunt J, et al. Atezolizumab as first-line treatment in cisplatin-ineligible patients with locally advanced and metastatic urothelial carcinoma: a single-arm, multicentre, phase 2 trial. Lancet 2017;389(10064):67-76.

18. Balar AV, Castellano D, O'Donnell PH, Grivas P, Vuky J, Powles T, et al. First-line pembrolizumab in cis- platin-ineligible patients with locally advanced and unresectable or metastatic urothelial cancer (KEYNOTE-052): a multicentre, single-arm, phase 2 study. Lancet Oncol 2017;18(11):1483-92.

19. Mazza C, Escudier B, Albiges L. Nivolumab in renal cell carcinoma: latest evidence and clinical potential. Ther Adv Med Oncol 2017;9(3):171-81.

20. Xu F, Xu L, Wang Q, An G, Feng G, Liu F. Clinicopathological and prognostic value of programmed death ligand-1 (PD-L1) in renal cell carcinoma: a meta-analysis. Int J Clin Exp Med 2015;8(9):14595-603.

21. Choueiri TK, Figueroa DJ, Fay AP, Signoretti S, Liu Y, Gagnon R, et al. Correlation of PD-L1 tumor expression and treatment outcomes in patients with renal cell carcinoma receiving sunitinib or pazopanib: results from COMPARZ, a randomized controlled trial. Clin Cancer Res 2015;21(5):1071-7.

22. Callea M, Albiges L, Gupta M, Cheng SC, Genega EM, Fay AP, et al. Differential Expression of PD-L1 between Primary and Metastatic Sites in Clear-Cell Renal Cell Carcinoma. Cancer Immunol Res 2015;3(10):115864.

23. Hirayama Y, Gi M, Yamano S, Tachibana H, Okuno T, Tamada S, et al. Anti-PD-L1 treatment enhances antitumor effect of everolimus in a mouse model of renal cell carcinoma. Cancer Sci 2016;107(12):1736-44.

24. Rizvi NA, Hellmann MD, Snyder A, Kvistborg P, Makarov V, Havel JJ, et al. Cancer immunology. Mutational landscape determines sensitivity to PD-1 blockade in non-small cell lung cancer. Science 2015;348(6230):124-8.

25. Ilie M, Hofman V, Dietel M, Soria JC, Hofman P. Assessment of the PD-L1 status by immunohistochemistry: challenges and perspectives for therapeutic strategies in lung cancer patients. Virchows Arch 2016;468(5):511-25.

26. Patel SP, Kurzrock R. PD-L1 Expression as a Predictive Biomarker in Cancer Immunotherapy. Mol Cancer Ther 2015;14(4):847-56.

27. Isaacsson Velho P, Antonarakis ES. PD-1/PD-L1 pathway inhibitors in advanced prostate cancer. Expert Rev Clin Pharmacol 2018;11(5):475-86.

28. Haffner MC, Guner G, Taheri D, Netto GJ, Palsgrove DN, Zheng Q, et al. Comprehensive Evaluation of Programmed Death-Ligand 1 Expression in Primary and Metastatic Prostate Cancer. Am J Pathol 2018;188(6):1478-85.

29. De Bono JS, Goh JC, Ojamaa K, Piulats Rodriguez JM, Drake CG, Hoimes CJ, et al. KEYNOTE-199: Pembrolizumab (pembro) for docetaxel-refractory metastatic castration-resistant prostate cancer (mCRPC). J Clin Oncol 2018;36(15_suppl):5007. 
30. Boudadi K, Suzman DL, Anagnostou V, Fu W, Luber $\mathrm{B}$, Wang $\mathrm{H}$, et al. Ipilimumab plus nivolumab and DNA-repair defects in AR-V7-expressing metastatic prostate cancer. Oncotarget 2018;9(47):28561-71.

31. Chan TA, Yarchoan M, Jaffee E, Swanton C, Quezada SA, Stenzinger A, et al. Development of tumor mutation burden as an immunotherapy biomarker: utility for the oncology clinic. Ann Oncol 2019;30(1):44-56.

32. Van Allen EM, Miao D, Schilling B, Shukla SA, Blank C, Zimmer L, et al. Genomic correlates of response to CTLA-4 blockade in metastatic melanoma. Science 2015;350(6257):207-11.

33. Turajlic S, Litchfield K, Xu H, Rosenthal R, McGranahan N, Reading JL, et al. Insertion-and-deletion-derived tumour-specific neoantigens and the immunogenic phenotype: a pan-cancer analysis. Lancet Oncol 2017;18(8):1009-21.

34. Le DT, Durham JN, Smith KN, Wang H, Bartlett BR, Aulakh LK, et al. Mismatch repair deficiency predicts response of solid tumors to $\mathrm{PD}-1$ blockade. Science 2017;357(6349):409-13.

35. Chalmers ZR, Connelly CF, Fabrizio D, Gay L, Ali SM, Ennis R, et al. Analysis of 100,000 human cancer genomes reveals the landscape of tumor mutational burden. Genome Med 2017;9(1):34.

36. Marcus L, Lemery SJ, Keegan P, Pazdur R. FDA Approval Summary: Pembrolizumab for the Treatment of Microsatellite Instability-High Solid Tumors. Clin Cancer Res 2019;25(13):3753-8.

37. Ericson KM, Isinger AP, Isfoss BL, Nilbert MC. Low frequency of defective mismatch repair in a population-based series of upper urothelial carcinoma. BMC Cancer 2005;5:23.

38. Zhu J, Armstrong AJ, Friedlander TW, Kim W, Pal SK, George DJ, et al. Biomarkers of immunotherapy in urothelial and renal cell carcinoma: PD-L1, tumor mutational burden, and beyond. J Immunother Cancer 2018;6(1):4. 